\title{
Aprendizagem Baseada em Projeto simulando o Método de Design Sprint: "5 dias" em um Semestre
}

\author{
Soraia Silva Prietch \\ Universidade Federal de Mato Grosso \\ Rondonópolis-MT, Brasil \\ soraia.roo@gmail.com
}

\author{
Mickael Langstton Costa Alves \\ Universidade Federal de Mato Grosso \\ Rondonópolis-MT, Brasil \\ micklangstton@gmail.com
}

\begin{abstract}
The goal of this paper is to present a brief report of the Human-Machine Interface course' conduction, techniques used and some results delivered by students. The theme of application during the semester was "Engaged Communities", according to the Call for Design Competition for Students of CHI'18. From competition's instructions, we simulated Design Sprint sections, during one semester, as a strategy to organize design proposals and learning assessment.
\end{abstract}

\section{Author Keywords}

HCI education; Design Sprint; HCI life cycle.

\section{ACM Classification Keywords}

H.1.2 User/Machine Systems. H.5.2 User Interfaces. K.6.1 Project and People Management.

\section{INTRODUÇÃO}

Interface Homem-Máquina (IHM) é o nome da disciplina do curso de Sistemas de Informação (SI) em questão, cuja oferta foi iniciada em 2013, em sistema de crédito semestral sem pré-requisitos. Apesar de sua ementa ${ }^{1}$ se preocupar, preferencialmente, com tema voltado para interfaces, na prática os conteúdos são abordados de forma mais abrangente, incluindo no conteúdo programático métodos e técnicas sobre design de interação, experiência do usuário, codesign, dentre outras, podendo variar a cada semestre. Devido a essa flexibilidade, todos os envolvidos se referem à disciplina como IHC (Interação Humano-Computador).

Permission to make digital or hard copies of all or part of this work for personal or classroom use is granted without fee provided that copies are not made or distributed for profit or commercial advantage and that copies bear this notice and the full citation on the first page. Copyrights for components of this work owned by others than the author(s) must be honored. Abstracting with credit is permitted. To copy otherwise, or republish, to post on servers or to redistribute to lists, requires prior specific permission and/or a fee. Copyright 2018 SBC.

IHC 2018, Anais Estendidos do XVII Simpósio Brasileiro sobre Fatores Humanos em Sistemas Computacionais

Outubro 22-26, 2018, Belém, Brasil

Workshop sobre Educação em IHC (WEIHC)

\footnotetext{
1 Ementa: "Conceitos de usabilidade. Elementos do projeto de interface humano-computador. Projeto de interface humano-computador. Avaliação de interfaces". [5]
}

Devido ao curso ser Sistemas de Informação e ter como foco de interesse, pela maioria dos estudantes, a indústria como mercado de trabalho, no semestre 2017/2, a professora responsável pela disciplina propôs um tema de aplicação fio conductor para discutir a teoria ao longo do semestre. Esse tema foi a chamada da Competição de Design para Estudantes (Student Design Competition) [16] da Conferência Internacional sobre Fatores Humanos em Sistemas Computacionais 2018 (ACM CHI Conference on Human Factors in Computing Systems), a qual teve como foco as Comunidades Engajadas (Engaging Communities).

A chamada da Competição previa o uso de abordagens de Design Centrado no Usuário para desenvolver novas formas para dar suporte, empoderar ou mudar o comportamento de um grupo a respeito de uma área ou assunto de comum interesse. Com relação às Comunidades Engajadas, conforme as regras, se poderia trabalhar com comunidades existentes ou se poderia criar uma nova comunidade. No que se referiam às estratégias, recomendavam àquelas que permitissem engajamento, como design participativo, cocriação e codesign, design de serviços, design para inovação social, design inclusivo e inovação aberta. Com respeito à tecnologia, sugeriram a inclusão de impressão 3D, big data, redes sociais, IoT, gamificação, sensores e atuadores, realidade aumentada/virtual, ou outras.

A partir das instruções da competição, definiu-se o uso do Design Sprint [7] como estratégia para organizar os projetos com ideias inovadoras e as avaliações. Esse método foi escolhido devido à sua capacidade de favorecer a entrega de subprodutos após cada aplicação de técnica sugerida, o que torna prática a aplicação da teoria e pode vir a motivar os estudantes em serem mais participativos nas aulas. Além do método de Design Sprint e das normas da Competição de Design mencionados, outras referências $[2,4,5,6,8,9,11$, $12,13,14]$ foram utilizadas na disciplina, as quais conferem suporte teórico e explicam os mecanismos que devem ser usados para a aplicação das técnicas selecionadas.

Nesse contexto, o objetivo desse artigo é apresentar o relato da condução da disciplina de Interface Homem-Máquina, as 
técnicas utilizadas e alguns resultados entregues pelos estudantes ao realizar atividades avaliativas dos conteúdos.

O artigo está organizado nas seguintes seções: a seção 2 traz definições básicas sobre o método de Design Sprint, a seção 3 descreve sobre o planejamento da simulação dos "5 dias" em um semestre, a seção 4 relata sobre as técnicas utilizadas e alguns resultados obtidos pelos estudantes ao longo do semestre, e a seção 5 traz as considerações finais.

\section{DESIGN SPRINT}

O Design Sprint é uma metodologia ágil que estabelece mecanismos para viabilizar a proposição de um projeto em um curto período de tempo. Esta metodologia, se bem conduzida e a equipe for bem composta, apresenta alto nível de alcançabilidade dos objetivos e fornece as ferramentas para a construção de um protótipo realista e interativo em apenas cinco dias. O Sprint se adequa a pequenos e grandes projetos que vão desde um trabalho universitário até a criação de uma nova aplicação para uma grande corporação. Segundo os autores [7], este curto período de tempo dedicado à prototipação se deve ao fato da equipe trabalhar melhor sob pressão, aumentando o foco e evitando conversas e ações desnecessárias para a concretização do projeto. Antes de partir para a metodologia em si, há uma pré-organização para estruturar o local e a equipe que detenha conhecimentos diversos, existindo a possibilidade de adesão de especialistas ao projeto. Após a pré-organização é iniciado o trabalho na semana, de segunda a sexta-feira.

$\mathrm{Na}$ Segunda-Feira, com a equipe estabelecida, sendo sugerido como número ideal sete integrantes, o primeiro passo é elencar um objetivo a longo prazo em que todos estejam de acordo. Em seguida, a equipe elabora um diagrama para atingir o objetivo a longo prazo, continuamente selecionando o que mais se adequa ao objetivo final. Posteriormente, o diagrama e as ideias levantadas passam por uma revisão pelos membros da equipe e um especialista (ou mais) que podem readequar itens para o diagrama ficar enxuto. Por fim, é estabelecido um alvo em que o esforço coletivo deverá se concentrar.

$\mathrm{Na}$ Terça-Feira, são listadas as ideias que possam inspirar uma significativa contribuição no projeto, seguindo como referência elementos ou ferramentas já existentes (correlatas e inspiradoras). Em seguida, usando as ideias filtradas, são formulados esboços que serão apreciados na Quarta-feira.

$\mathrm{Na}$ Quarta-Feira, os esboços de soluções para atingir o objetivo a longo prazo serão avaliados pela equipe, sendo escolhida(s) a(s) melhor(es) solução(ões), pelo(s) Definidor(es) do projeto (pessoas com expertise e visão). Caso haja mais de um esboço vencedor, a equipe deve discutir de forma rápida se irão prototipar os esboços vencedores ou se irão agrupar os esboços em um único protótipo. Com o esboço definido, a equipe elaborará um storyboard que servirá como enredo (cenário de uso) para posterior avaliação do protótipo.
Na Quinta-Feira, o protótipo é fabricado por meio da divisão de tarefas entre a equipe, que o constroem por partes e o finalizam agrupando.

Na Sexta-Feira, após o protótipo concluído, é chegada a etapa de avaliação do protótipo, ao todo cinco potenciais clientes ou potenciais usuários participam. Através das avaliações são coletadas informações e padrões que gerem resultados consistentes sobre o projeto, mostrando seu potencial de sucesso (para produção em escala, para ampliação da adesão, dentre outros).

\section{PLANEJAMENTO DOS “5 DIAS” EM UM SEMESTRE}

O planejamento dos conteúdos do semestre foi organizado em três etapas, as quais foram concluídas com a entrega de um relatório cada. Para a entrega dos relatórios R1, R2 e R3 um cronograma foi previsto no início do semestre, os alunos deveriam criar pastas individuais em armazenamento na nuvem e postar no Ambiente Virtual de Aprendizagem (AVA) institucional um arquivo texto contendo o link de sua pasta-relatório. Além disso, no último dia de aula foram realizadas as apresentações orais dos três relatórios, adicionando suas conclusões de aprendizado.

Essas três etapas consistiram na discussão dos conteúdos relacionados aos 5 dias previstos do Design Sprint, organizados conforme a seguir. Na "Segunda-feira": mapeie, com reconhecimento do problema, do contexto, do públicoalvo, e definição do objetivo. "De Terça-feira a Quintafeira": faça esboços, decida e construa o protótipo, com concepção e construção de versão interativa de protótipos. $\mathrm{Na}$ "Sexta-feira": teste, com avaliação do protótipo com potenciais usuários. Sendo assim, cada relatório deveria contemplar o caminho percorrido contendo as técnicas aplicadas e os resultados obtidos.

Apesar do Design Sprint recomendar que a experiência ideal do uso do método em apenas 5 dias, vivenciamos isso em 16 encontros de 4 horas cada. A "Segunda-feira" teve duração de $02 / 10$ a 27/11/2017, com 06 encontros e entrega do R1 dia 04/12/2017. O período "de Terça-feira a Quinta-feira" ocorreu de 04/12/2017 a 22/01/2018, com 04 encontros e entrega do R2 dia 12/02/2018. A "Sexta-feira" teve duração de 29/01 a 26/02/2018, com 05 encontros e entrega do R3, na mesma data $(05 / 03 / 2018)$ das apresentações finais.

A ideia de realizar menos encontros na etapa de concepção e prototipação foi que, como o semestre letivo seria interrompido por férias devido à reestruturação do calendário acadêmico causada pela última greve, os estudantes "teoricamente" teriam mais tempo para se dedicar a essa etapa. Isso porque a disciplina não tem como foco ensinar o uso de ferramentas de prototipação ou de linguagens de programação. No entanto, foi necessário prever período de entrega do R2 com um prazo estendido de três semanas após o encerramento dos conteúdos sobre o assunto.

A forma como os estudantes trabalharam foi uma decisão tomada pela professora com base nas experiências prévias (de 2013/2 a 2017/1) ao semestre em questão. Tais 
experiências evidenciaram que relatórios desenvolvidos e entregues em grupo dificultavam as avaliações individuais de aprendizagem, que vários estudantes demonstravam dificuldades de interação em equipe e que muitas desistências ocorriam no início e ao longo do semestre. Essa forma de trabalho contemplava aplicações de técnicas individuais e em grupo (com a turma inteira), porém as entregas dos relatórios foram individuais.

É importante mencionar que a teoria foi ministrada ao longo do semestre, sendo que em cada aula foi possível intercalar com as atividades práticas dos projetos. A Aprendizagem Baseada em Projeto (PBL, Problem-based Learning) precisa ser apoiada na teoria para garantir que a prática não seja vazia e sem sentido; a teoria explica os conceitos, as motivações, os objetivos e a metodologia de condução das técnicas, bem como os objetivos de aprendizagem da disciplina. $[3,15]$

\section{TÉCNICAS UTILIZADAS E ALGUNS RESULTADOS OBTIDOS PELOS ESTUDANTES}

Ao início de cada etapa uma checklist era apresentada, explicada e disponibilizada no AVA, relacionando os resultados das atividades que precisavam ser entregues e suas respectivas pontuações. As atividades foram realizadas em sala de aula ou no laboratório de informática, individualmente e/ou com a participação da turma, mas as entregas dos relatórios e as avaliações foram feitas de maneira individual. Na sequência, são descritas as etapas.

\section{Etapa 1: "Segunda-feira"}

A checklist do R1 contou com as seguintes atividades: (i) Definir o tema; (ii) Definir o objetivo; (iii) Levantar os potenciais problemas (ideias pessimistas); (iv) Relacionar oportunidades; (v) Elaborar o Mapa; (vi) Identificar as partes interessadas no artefato de CoDesign; (vii) Listar relação de inclusão e de exclusão para definir as partes interessadas; (viii) Elaborar questionário, aplicar online, efetuar tabulação e discutir brevemente os resultados; Buscar e descrever dados dos (ix) sistemas correlatos ao foco de aplicação; e, (x) sistemas inspiradores, independente do foco de aplicação.

A condução das atividades em turma, porém com resultados entregáveis individuais, foi realizada, em sua maioria, seguindo o estilo apresentado na Figura 1. Essa é uma técnica usada com frequência no Design Sprint com o objetivo de que os participantes presentes não sejam influenciados, inicialmente, pelas respostas dos colegas.

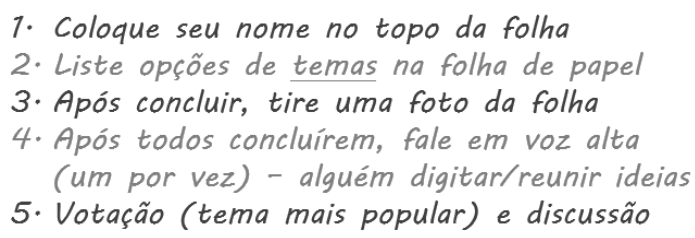

Figura 1. Passos para condução das atividades em turma.

Dentre os 14 estudantes presentes nessa aula, cada um listou de 1 a 3 temas diferentes, não havendo repetições. A votação (em, no máximo, 3 temas) e a discussão ocorreram em paralelo uma vez que cada voto era seguido de uma justificativa passível de debate. Ao final, o tema mais popular foi "Algo que facilite o ingresso no mercado de trabalho por egressos do curso de SI", com 08 votos. Ainda seguindo os passos da Figura 1, o objetivo definido foi "Auxiliar que os concluintes do curso estejam empregados ou possuam propostas de emprego ao final do curso". Como observado, a turma definiu que a solução a ser proposta deveria ser restrita para estudantes e egressos do curso de Sistemas de Informação da Universidade em questão.

A mesma técnica condução apresentada na Figura 1 também foi usada para levantar os problemas e as oportunidades. Com respeito aos problemas, 09 itens foram listados, a citar alguns: "desinteresse dos empregadores em usar a solução"; "descobrir que ao invés de ajudar, [a aplicação] repercute em alguma barreira". No que tange às oportunidades, foram definidas 04 categorias: identificar vagas existentes, receber divulgação das vagas em primeira mão, evidenciar competências que o aluno tem e conferir visibilidade ao currículo. Dentro de cada uma dessas quatro categorias, foram relacionadas diversos itens.

O mapa, um diagrama proposto no Design Sprint, foi feito individualmente, incentivados à os compartilhar no AVA e incluir ideias dos colegas (incluindo rótulos com seus nomes) em suas propostas de mapa. No entanto, os estudantes tiveram dificuldades em elaborar seus mapas, uma vez que foi evidente a integração de conhecimentos de diagramas aprendidos em disciplinas de Engenharia de Software, tornando o mapeamento mais complexo.

Para relacionar as partes interessadas, nessa ocasião contávamos com 10 estudantes presents, que utilizaram o artefato de CoDesign, considerando as 04 escalas dentre potenciais usuários diretos à indiretos. A partir desse resultado e dos critérios de inclusão e exclusão elaborados pelos estudantes, eles votaram nos seguintes públicos: Empresários dispostos a contratar profissionais sem experiência, Alunos já empregados em empresas da área, e Alunos que pensam resolver problemas usando tecnologia.

Para elaborar e aplicar o questionário online, com o intuito de conhecer o perfil, as opiniões e as vivências dos representantes das partes interessadas definidas, a turma se organizou em 02 equipes (EQ1 e EQ2) com 04 estudantes e 01 equipe (EQ3) com 03 estudantes.

A equipe EQ1 ficou responsável pelas partes interessadas "Alunos já empregados em empresas da área", e elaborou um questionário online com 06 questões de perfil e 09 sobre opiniões e vivência. No total, obtiveram 03 respostas, sendo 01 respondente do sexo feminino e todos egressos do curso de SI. Em resumo, os respondentes mencionaram que existe demanda no mercado por profissionais da área, no entanto, as empresas buscam pessoas com conhecimentos específicos; e também se pode optar por empreender. Informaram que é importante para facilitar a conquista de uma vaga: identificar sua principal subárea de interesse 
dentro da graduação antes de concluir o curso, manter o currículo atualizado, estar aberto ao diálogo e saber se comunicar, ser proativo, e buscar outras formas de qualificação/ se atualizar além do curso de graduação. Conforme os respondentes, as disciplinas-chave do curso para conquistar um emprego dependerão dos objetivos e afinidades do estudante com sua subárea de maior interesse. Para eles, há que se conhecer o enfoque da graduação escolhida, de preferência antes de ingressar no curso.

A equipe EQ2 ficou responsável pelas partes interessadas "Empresários dispostos a contratar profissionais sem experiência", e elaborou um questionário online com 05 questões de perfil e 10 sobre opiniões e vivência. No total, obtiveram 02 respostas, sendo 01 responsável pelo setor de TI de uma empresa e 01 diretor de uma empresa, com, respectivamente, 30 e 10 anos de experiência. Em resumo, os respondentes mencionaram que buscam pessoas que saibam trabalhar em equipe e que sejam comprometidas, e que o processo de recrutamento de novos profissionais consiste na análise curricular, na realização de entrevista ou pela indicação por pessoas de sua confiança. As empresas não oferecem plano de carreira, em uma delas a faixa etária preferencial busca por profissionais com idade entre 25 e 35 anos, e foi informado que o tempo que um profissional permanece na empresa é "acima de um ano" e "cinco anos".

A equipe EQ3 ficou responsável pelas partes interessadas "Alunos que pensam em resolver problemas usando tecnologia", e elaborou um questionário online com 05 questões de perfil e 09 sobre opiniões e vivência. No total, obtiveram 10 respostas, sendo 07 respondentes do sexo masculino e todos estudantes matriculados no curso de SI. Em resumo, informaram como estratégias: manter contato com pessoas que trabalham na área, buscar vagas em websites e agências de emprego, realizar outros cursos além da graduação; e, dentre as dificuldades mencionaram, em sua maioria, a falta de experiência. Os respondentes se mantém atualizados sobre vagas em sua área de interesse por meio das redes sociais, sites e agências de emprego, notícias, indicação ou informação de outras pessoas, amigos, observação do mercado enquanto atua em outra área, e, há estudantes que mencionaram não procurar. As áreas de interesse mais mencionadas foram desenvolvimento $\mathrm{e}$ análise de sistemas. Sobre buscar vagas na cidade, as opiniões são diversas, desde "difícil encontrar" passando por "não sei informar" até "não é difícil encontrar". A maioria dos respondentes mencionaram não se sentir preparados pelo curso de graduação para ingressar no mercado de trabalho.

Com respeito aos Sistemas correlatos e aos Sistemas inspiradores, cada estudante buscou 01 sistema "concorrente" da solução a ser proposta e 01 sistema com interface atraente e/ou com forma de interação diferenciada como inspiração para o design da solução a ser proposta. A partir da busca, cada estudante publicou em um fórum aberto no AVA e documentou os resultados das buscas (link de acesso/download, captura de tela (imagem) para ilustração da aplicação, e lista com, pelo menos, três pontos positivos da solução). No total, foram documentados 06 sistemas correlatos e 08 sistemas inspiradores.

\section{Etapa 2: "De Terça-feira a Quinta-feira"}

A checklist do R2 contou com as seguintes atividades: (i) Preencher o Quadro de Avaliação; (ii) Registrar técnica de BrainDrawing; (iii) Elaborar cenário de uso (textual ou pictográfico); (iv) Revisar e redesenhar mapa; (v) Elaborar wireframes de uma tarefa escolhida no mapa; (vi) Organizar fluxo da tarefa; e, (vii) Projetar protótipo navegável.

Com relação ao preenchimento do Quadro de Avaliação [1], a atividade foi conduzida conforme a Figura 1. Seis estudantes participaram dessa atividade, sendo que alguns dos problemas levantados foram os seguintes: "Alunos do Curso de SI, não sabem quando uma vaga de emprego na qual eles concorrem foi preenchida"; "Como anunciar as vagas e saber se estas estão sendo atendidas e informar se ainda [estão] disponíveis?"; "Se a plataforma é restrita para alunos do curso de SI, como será feita a validação?'. A seguir constam algumas ideias e soluções levantadas: "Sistema notifica que uma vaga na qual um candidato concorre, foi encerrada"; "Usuários de empresas em subsistema da aplicação acompanham o preenchimento das vagas, removendo, alterando e adicionando as mesmas"; "Para alunos do curso, informar o número de matrícula e comprovante de matrícula no semestre vigente. Para concluintes [egressos] enviar o certificado [diploma]".

A técnica de BrainDrawing [1] foi aplicada em uma aula, na qual constavam 04 (quatro) estudantes presentes. Sentados em círculo, lado a lado, cada estudante com uma folha em branco deveria desenhar, em 2 minutos, uma interface referente à alguma das ideias/ soluções que havia pensado anteriormente. Transcorrido esse tempo, a folha deveria ser passada ao colega ao lado em sentido horário. Durante 2 minutos, o colega deveria analisar a proposta e desenhar algum elemento de interface como forma de melhoria. A rotação da folha ocorreu de 2 em 2 minutos até que a folha retornasse ao seu proponente inicial. A partir dos resultados, cada estudante deveria informar quais sugestões ele(a) acataria e quais não acataria, com justificativa, para dar continuidade à concepção de seu protótipo.

A partir do mapa revisado e/ou redesenhado, foi solicitado que cada estudante escolhesse uma tarefa para elaborar propostas de interfaces usando wireframes, individualmente, porém a tarefa deveria envolver, pelo menos, um tipo de busca ou um formulário iniciando pela tela inicial o(s) caminho(s) para alcance do objetivo. Alguns estudantes decidiram desenhar seus wireframes em papel, outros utilizaram ferramenta digital. Tendo os wireframes feitos, pediu-se para organizar individualmente o fluxo da tarefa, mostrando o caminho passo a passo desde a tela inicial até o alcance do objetivo. Esse fluxo poderia ser representado por mais de um caminho, caso desejassem. 
Ao final, na Etapa 2, 07 estudantes entregaram o Relatório 2, incluindo os protótipos navegáveis, desenvolvidos com alguma ferramenta de prototipação, de escolha deles. Durante a concepção e a construção do protótipo interativo, pode-se verificar que as ideias de conteúdos para cadastros $\mathrm{e}$ filtros de busca foram semelhantes, uma vez que a turma vinha discutindo os potenciais pontos de interesse das partes interessadas. Contudo, os desenhos das interfaces foram diferentes uns dos outros, além do fato de alguns optarem por disponibilizar a solução em diferentes meios: 05 escolheram somente aplicativo para dispositivo móvel, 01 escolheu solução para web, e 01 escolheu disponibilizar a solução em tela grande, sensível ao toque, para acesso em local público.

\section{Etapa 3: "Sexta-feira"}

A checklist do R3 contou com as seguintes atividades: (i) Responder perguntas iniciais como forma de preparação para a avaliação; (ii) Realizar avaliação piloto; (iii) Realizar avaliações efetivas; e, (iv) Avaliar a disciplina.

O porquê e o que avaliar pensados pelos estudantes, como forma de preparação para a avaliação, foram semelhantes mesmo tendo sido elaborados conforme condução da Figura 1 e visto que os conceitos da disciplina sobre usabilidade e experiência positiva do usuário estavam mais consolidados nessa etapa do semestre. A partir disso, cada estudante elaborou sua documentação, a partir dos modelos disponibilizados no AVA, para o planejamento e execução da avaliação piloto. A documentação consistiu em: roteiro para o pesquisador, termo de consentimento livre e esclarecido, questionários de perfil e de satisfação, descrição da tarefa, ficha de observação, bem como a indicação para preparação de equipamentos para registro fotográfico e gravação da tela. Vale notar que apesar de utilizarem os mesmos modelos, as tarefas e os questionamentos aos participantes não foram padronizados. Um exemplo de tarefa definida por um dos estudantes foi: "A partir da página inicial (Home), efetue a busca por uma vaga de programador, aplique filtros para melhorar a pesquisa, selecione a vaga de seu interesse, confirme a vaga e volte para a tela de Home".

Os documentos deveriam ser entregues no Relatório 3 preenchidos, escaneados e assinados, caso fossem em papel (como o termo e a ficha de observação), ou somente preenchidos, caso fossem digitais (como os questionários de perfil e de satisfação). Essa atividade foi definida para ser realizada com os próprios alunos da turma como participantes, em sala de aula. Essa decisão foi tomada de modo que a professor pudesse observar os estudantes como moderadores e observadores, anotasse os comentários e explicasse a todos ao final os pontos positivos e negativos, e como poderiam contornar determinadas situações "difíceis".

As mesmas regras definidas para a avaliação piloto foram definidas para a avaliação efetiva, incluindo os mesmos itens de comprovação documental e imagética da avaliação piloto; porém, com três diferenças. A primeira, que os participantes voluntários deveriam ser colegas de curso fora da turma ou empresários da cidade; a segunda, que cada estudante da turma deveria realizar 02 (duas) avaliações efetivas do protótipo; e, a terceira, que não seria obrigatória a realização das avaliações efetivas em sala de aula, somente para quem desejasse. Essa última regra foi definida porque existiam estudantes que moravam em outras cidades e para que pudessem realizar avaliações com empresários durante o dia, visto que a graduação ocorre no período noturno.

Dentre os 07 estudantes da turma, somente um realizou uma avaliação efetiva, os demais avaliaram seus protótipos com dois participantes. Sendo assim, 13 participantes foram entrevistados, 11 do sexo masculino e 02 do feminino, com a média de idade de 24 anos. Dentre eles, 09 já utilizou alguma aplicação para busca de empregos; porém, alguns informaram ter experiências não muito positivas, por falta de informações suficientes sobre o empregador ou sobre a vaga. Além disso, uma das participantes mencionou a dificuldade de ter que concorrer com homens à determinadas vagas.

As fichas de observação de dois estudantes estavam incompletas, portanto para o cálculo das médias referentes ao tempo de realização de tarefa, de solicitação de ajuda ao moderador e classificação de sucesso foi levado em consideração a quantidade de dados existentes. A média de tempo total (desde a explicação do termo de consentimento até o agradecimento final pela participação) de cada avaliação efetiva foi, em torno de, 23 minutos (a duração mais alta foi de $32 \mathrm{~min}$ e a mais baixa $09 \mathrm{~min}$ ). A média de tempo de realização da tarefa usando o protótipo foi, em torno de, 05 minutos (a duração mais alta foi de 11 min e a mais baixa $01 \mathrm{~min}$ ). Dentre 11 respostas preenchidas, 06 solicitaram ajuda ao moderador durante a realização da tarefa e a média de classificação de sucesso atribuída pelo moderador foi 3.9 ( 2 com nota 5, 6 com 4, e 3 com 3 ).

No que se refere aos questionários de satisfação, após realização da tarefa usando os protótipos, os participantes conferiram feedback para melhorias. A relação de melhorias, considerando os 07 protótipos, é a seguinte: incluir mensagens ou tutorial para instruir o usuário; revisar botão confirmar que precisa ser clicado duas vezes; direcionar usuário para a tela/página correta; incluir legenda nos ícones; garantir caminhos mais curtos; incluir rótulos faltantes ou mais fáceis de se identificar; conferir mais clareza na visualização dos resultados; inserir feedback ao usuário após confirmação/ envio; permitir anexar currículo ao invés de preencher formulário; permitir que a empresa envie e-mail/ mensagem para candidatos; visualizar os dados do próprio cadastro para alterar, se desejar; e, detalhar informações sobre a vaga como pré-requisitos e critérios de seleção.

Com relação à avaliação da disciplina por seis estudantes respondentes, mencionaram como pontos principais para auxiliar no desenvolvimento das propostas foram: definir o objetivo, identificar as partes interessadas e conhecê-los, elaborar o mapa e conhecer os sistemas correlatos e inspiradores. Um dos estudantes relatou que considerou interessante a perspectiva da disciplina, pois é a única que ele cursou que se preocupa com os potenciais usuários e 
proporciona contato com os mesmos durante o projeto de uma solução. $\mathrm{O}$ mesmo estudante mencionou que somente ao final da disciplina percebeu que deveria ter dado mais importância às regras de usabilidade de Nielsen, pois ao avaliar seu protótipo com os potenciais usuários várias falhas foram evidenciadas. Outro estudante considerou difícil pensar em como os conteúdos das disciplinas no curso de SI poderiam estar relacionados de modo que ao final do curso os alunos pudessem finalizar uma aplicação completa, pois cada disciplina é ministrada de forma isolada e restrita aos seus conteúdos específicos. Nesse aspecto, há que pensar em estratégias similares à apresentada por Marques e Melo [10]. Além disso, dois estudantes, que têm mais afinidade com programação, mencionaram que a prototipação foi a parte mais interessante da disciplina e o restante dos conteúdos acharam desinteressante.

\section{CONSIDERAÇÕES FINAIS}

Ao utilizar o método de Design Sprint, algumas técnicas precisaram ser adaptadas por não termos especialistas de diferentes áreas de conhecimentos e habilidades na turma; além disso, foi eliminada a figura do Definidor e todos tinham direito de voto igualitário.

Outro ponto que não foi incluído, nas soluções dos estudantes, como sugestão da competição de design foram as tecnologias: impressão 3D, big data, redes sociais, IoT, gamificação, sensores e atuadores, realidade aumentada/ virtual. $\mathrm{O}$ que se percebeu é que os estudantes propuseram soluções já conhecidas por eles, como, aplicativos para dispositivos móveis ou website, não trazendo inovações para debate. Uma hipótese é o receio de ter que prototipar algo que não conseguiriam representar com o conhecimento atual; mesmo após conhcerem a técnica Wizard of Oz.

Ao aplicar o questionário online na Etapa 1, apesar de poucos respondentes, verificamos alguns desinteressados em buscar vagas e desinteressados em atuar na área do curso. Essas respostas chamaram atenção e consideramos importante levar a discussão para o Núcleo Docente Estruturante (NDE) e propor a inclusão de algumas questões sobre motivação e vocação no questionário de avaliação do curso.

$\mathrm{Na}$ Etapa 3, em semestres anteriores, as avaliações efetivas poderiam ser realizadas externamente em turno e dia da semana diferentes da disciplina, porém os estudantes eram obrigados a filmar por completo cada avaliação. Nesse semestre, foram permitidas as avaliações externas, porém a filmagem não foi cobrada devido à demora para efetuar o upload dos vídeos pelos estudantes e depois o download pela professora. No entanto, essa demora pareceu pequena diante das dúvidas que surgiram ao avaliar o Relatório 3.

\section{REFERÊNCIAS}

1. Maria C.C. Baranauskas; Maria C.Martins; José A.Valente. 2013. Codesign de redes digitais: tecnologia e educação a serviço da inclusão social. Penso.
2. Simone D. J. Barbosa, Bruno S. Silva. 2010. Interação Humano-Computador. Elsevier.

3. Clodis Boscarioli. 2011. O Ensino de IHC por meio de Aprendizagem Baseada em Problemas: Um Relato de Experiência. II WEIHC, 10th IHC. Disponível em: goo.gl/JWtjWx, acesso dia 27/08/2018

4. Walter Cybis, Adriana H. Betiol, Richard Faust. Ergonomia e Usabilidade: Conhecimentos, Métodos e Aplicações. São Paulo: Novatec Editora, 2007.

5. Mara Andréa Dota; et al. 2009. Projeto Pedagógico do Curso de Graduação de Bacharelado em Sistemas de Informação. ICEN/ CUR, Universidade Federal de Mato Grosso.

6. Saul Greenberg, Sheelagh Carpendale, Nicolai Marquardt, Bill Buxton. 2012. Sketching User Experiences: The Workbook. Morgan Kaufmann.

7. Jake Knapp. 2017. Sprint: O Método usado no Google para Testar e Aplicar Novas Ideias em apenas Cinco Dias. Com John Zeratsky e Braden Kowitz. - 1.ed. - Rio de Janeiro: Intrínseca. 320p.

8. Steve Krug. 2006 Não me faça pensar. Editora: Alta Books, ISBN: 2147483647.

9. Jonathan Lazar, Jinjuan Heidi Feng, Harry Hochheiser. 2017. Research Methods in HumanComputer Interaction. 2nd. ed., Morgan Kaufmann.

10. Anna Beatriz dos S. Marques, Áurea H.da S.Melo. 2015. Relato de experiência no ensino de IHC em nível de graduação através de uma abordagem interdisciplinar. VI WEIHC, IHC, p. 13-16.

11. Jakob Nielsen. 1993. Usability Engineering. Morgan Kaufmann.

12. Donald A Norman. 2008. Design Emocional: Por que adoramos (ou detestamos) os objetos do dia-adia. Rio de Janeiro: Rocco.

13. Yvonne Rogers; Helen Sharp; Jennifer Preece. 2013. Design de Interação: Além da Interação Humano-Computador. Bookman.

14. Jeffrey Rubin, Dana Chisnell. 2008. Handbook of Usability Testing: How to Plan, Design, and Conduct Effective Tests. 2a ed., Wiley Publishing.

15. Hyo-Jeong So, Bosung Kim. 2006. Conflicts in pedagogical and technical knowledge: pre-service teachers' understanding and misconception of integrating technology into PBL lessons. 7th Inter. Conf. on Learning sciences (ICLS), p. 994-995.

16. Student Design Competition. CHI 2018. Disponível em: https://chi2018.acm.org/authors/student-designcompetition/, acesso dia: 04/06/2018. 